\title{
The risk to import ESBL-producing Enterobacteriaceae and Staphylococcus aureus through chicken meat trade in Gabon
}

Frieder Schaumburg ${ }^{1,2 *}$, Abraham S Alabi ${ }^{2,3}$, Lisa Frielinghaus ${ }^{1,2}$, Martin P Grobusch ${ }^{2,3,4}$, Robin Köck ${ }^{5}$, Karsten Becker ${ }^{1}$, Saadou Issifou ${ }^{2,3}$, Peter G Kremsner ${ }^{2,3}$, Georg Peters ${ }^{1}$ and Alexander Mellmann ${ }^{5}$

\begin{abstract}
Background: A main export market for chicken meat from industrialized countries is sub-Saharan Africa. We hypothesized that antibiotic resistant bacteria could be exported to developing countries through chicken meat trade. The objective was to investigate the occurrence and molecular types of ESBL-producing Enterobacteriaceae and Staphylococcus aureus in chicken meat in Gabon and to assess their dissemination among humans.

Results: Frozen chicken meat samples imported from industrialized countries to Gabon $(n=151)$ were screened for ESBL-producing Enterobacteriaceae and S. aureus. Genotypes and resistance genes (SHV, TEM, CTX-M, CMY-2) of isolates from meat were compared with isolates derived from humans.

The contamination rate per chicken part (i. e. leg, wing) with ESBL-producing Escherichia coli (ESBL E. coli, no other ESBL-producing Enterobacteriaceae were found) and S. aureus was $23 \%$ and $3 \%$, respectively. The beta-lactamase CTX-M 1 was predominant in ESBL E. coli from meat samples but was not found in isolates from cases of human colonization or infection. S. aureus belonging to spa type t002 (multilocus sequence type ST5) were found both in chicken meat and humans.
\end{abstract}

Conclusion: There is a risk to import ESBL E. coli to Gabon but molecular differences between isolates from humans and chicken meat argue against a further dissemination. No MRSA isolate was detected in imported chicken meat.

Keywords: Staphylococcus aureus, Escherichia coli, Antimicrobial resistance, Chicken meat, Trade, Africa

\section{Background}

The global trade volume is steadily increasing and the exchange of various goods may contribute to economic wealth and development. However, global travel and trade bear the risk of transmitting pathogens through travelers or goods. While measles, syphilis, tuberculosis or smallpox have spread in the age of exploration and colonization, nowadays, new pathogens are emerging [1].

For instance, enterohemorrhagic Escherichia coli O104: H4, which caused an outbreak in central Europe in 2011, was most likely imported through seeds from Egypt [2]. Similarly, international travel, transfer of patients and

\footnotetext{
* Correspondence: frieder.schaumburg@ukmuenster.de

'Institute of Medical Microbiology, University Hospital Münster, Domagkstr. 10, 48149 Münster, Germany

${ }^{2}$ Centre de Recherches Médicales de Lambaréné, Albert Schweitzer Hospital, Lambaréné, Gabon

Full list of author information is available at the end of the article
}

medical tourists facilitate the import of various pathogens such as extended spectrum beta-lactamase (ESBL)and carbapenemase-producing Enterobacteriaceae or Panton-Valentine leukocidin (PVL) positive Staphylococcus aureus [3-5].

The frequent use of antibiotics - not only as therapeutics but also as growth promoters - has contributed to the emergence of antibiotic resistance in animal husbandry [6]. Hence, in European countries, industrially raised poultry and chicken can be contaminated with ESBL-producing E. coli (ESBL E. coli, up to 58-93.3\% of chicken) and methicillin-resistant $S$. aureus (MRSA, $0.7-37.2 \%$ of chicken) [7-12]. One study showed that contamination of food items with multidrug-resistant bacteria might be an important vehicle for the spread of antibiotic resistance [13].

While current literature mostly indicates an import of antimicrobial resistant pathogens from developing countries 
to the industrialized world, there is a potential transmission pathway for such bacteria, which is diametrically opposed: Many industrialized countries do not only produce poultry meat for their domestic market but also for export to low income or developing countries. The leading exporters of poultry meat in 2007 were the USA, Brazil and the Netherlands. Main import markets were sub-Saharan Africa and Asia (http://kids.fao.org/glipha).

Our hypothesis was that the import of meat from industrialized countries contributes to the emergence of multidrug resistance among humans in developing countries such as Gabon, Central Africa [14]. We therefore analyzed the contamination of chicken meat with ESBL-producing Enterobacteriacae (ESBL Enterobacteriaceae) and S. aureus in Gabon and compared genotypes of these pathogens with isolates from human carriage and infection.

\section{Results}

\section{Origin of samples}

In total, 151 chicken meat samples (88 legs, 63 wings) were analyzed. The chicken samples were frozen during shipment and storage in the supermarkets. Chicken meat was imported from the USA $(n=89)$, Spain $(n=60)$, Brazil and Turkey (each $\mathrm{n}=1$, Figure 1). No meat from domestic markets was sold in the five studied supermarkets in Lambaréné, Gabon.

\section{ESBL Enterobacteriaceae}

The prevalence of ESBL $E$. coli in chicken meat was $23 \%$ $(\mathrm{n}=14$ of 60 , Table 1). ESBL Enterobacteriaceae other than $E$. coli were not detected on the colorimetric media. We therefore included only ESBL $E$. coli isolates from human carriage and infection for comparison. Participants provided an informed consent prior to sampling. Isolates from humans came from already existing strain collections (Table 2). Among imported chicken meat in Gabon, ESBL E. coli was clearly associated with meat samples from Spain as the producing country $(\mathrm{OR}=\mathrm{Inf}$., 95\% CI: 7.5-Inf., p<0.001). The phylogenetic groups A and $\mathrm{B} 1$ were predominant in ESBL E. coli from chicken meat. In contrast, the other $E$. coli phylogenetic groups were more equally distributed among isolates from humans (Table 3). The beta-lactamases CTX-M 1 and CTX-M 14 were predominant in ESBL E. coli from

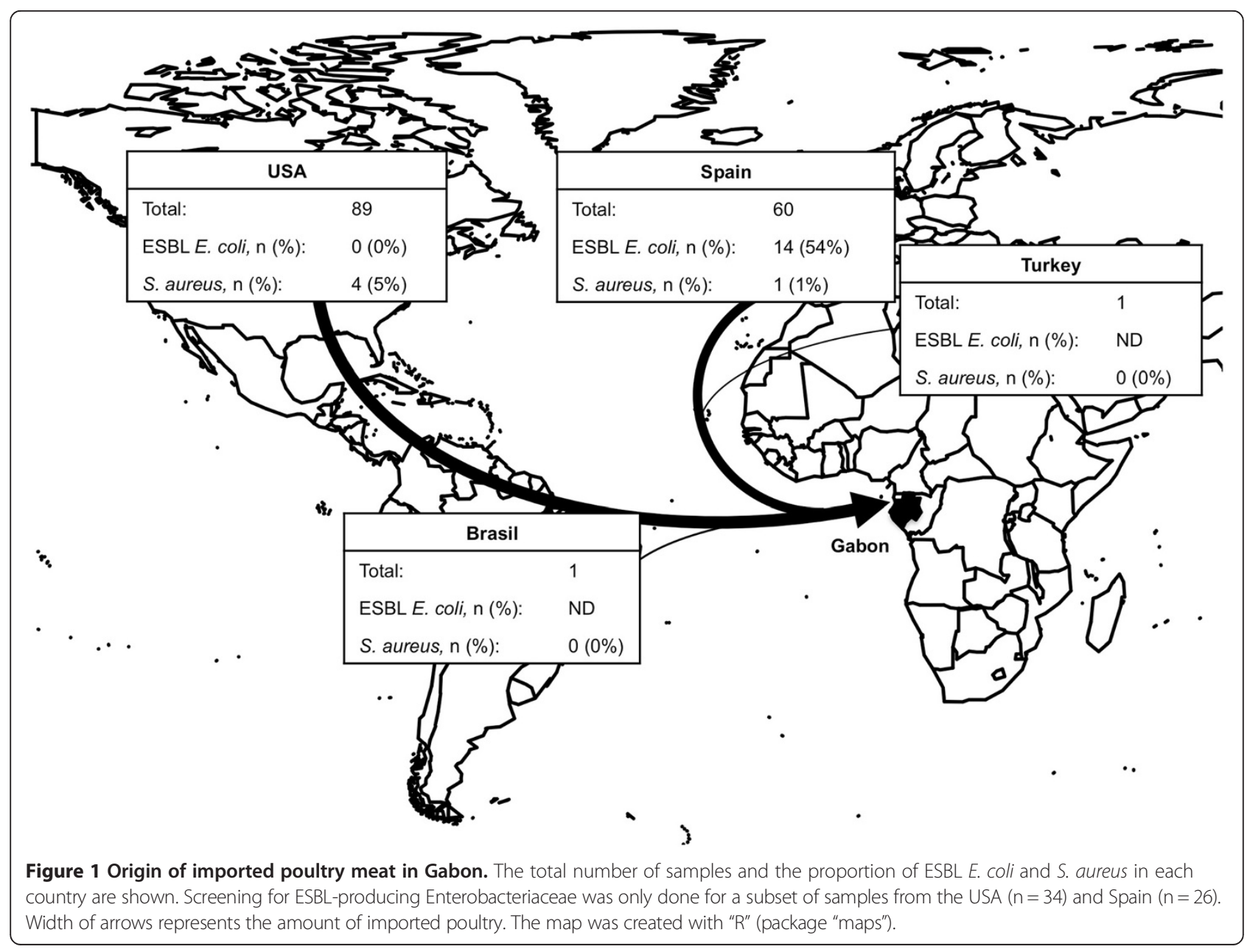


Table 1 Description of poultry samples from Gabon

\begin{tabular}{ll}
\hline & No. (\%) \\
\hline Imported chicken meat samples & $151(100 \%)$ \\
Samples screened for S. aureus & $151(100 \%)$ \\
Samples screened for ESBL E. coli & $60(39.7 \%)$ \\
ESBL E. coli & $14(23.3 \%)^{\mathrm{b}}$ \\
S. aureus & $5(3.3 \%)$ \\
\hline
\end{tabular}

${ }^{a}$ The consecutive screening for ESBL-producing Enterobacteria was started after the beginning of the study. Therefore not all meat samples were screened for ESBL-producing Enterobacteriaceae.

${ }^{\mathrm{b}}$ Three samples were contaminated with two different $E$. coli isolates. These isolates were phenotypically different and harbored different beta-lactamase encoding genes.

chicken meat. However, these beta-lactamases were not found in isolates from humans. In contrast, the predominant beta-lactamase in isolates from human carriage and infection was CTX-M 15 (Table 3). Other betalactamases (TEM, SHV) were also found in ESBL E. coli from chicken meat or human carriage and infection. The plasmid-mediated AmpC beta-lactamase CMY-2 was not detected among ESBL $E$. coli isolates.

The antibiotic resistance rates were lower in ESBL E. coli from chicken meat, compared to isolates from human carriage and infection (Table 3). The highest non-beta-lactam resistance in chicken meat was against ciprofloxacin $(\mathrm{n}=8)$. No resistance was detected against meropenem, imipenem or ertapenem.

\section{Staphylococcus aureus}

In total, $3 \%(\mathrm{n}=5)$ of all meat samples were contaminated with $S$. aureus in Gabon. No MRSA was detected as confirmed by the absence of mecA.

$S$. aureus was more frequently found in poultry meat from the USA (5\%) compared to Spain (1\%, Figure 1). Isolates from chicken meat mainly belonged to multilocus sequence type (MLST) clonal complex (CC) CC5 which was associated with sequence type ST5 and spa types t002 $(\mathrm{n}=3)$. Three so far unknown STs were detected and assigned to ST2622 (chicken, t386), ST2666 (human carriage, t084), ST2702 (human infection, t272, Table 4). Due to repeated amplification failure, we were unable to determine the ST for one isolates belonging to spa type t591 (chicken, MLST profile: ?-1-1-1-1-1-1, CC5).
Isolates belonging to t002 (ST5) were found in chicken meat and humans (Table 4). Of note, resistance rates for penicillin were always lower in isolates from chicken meat compared to isolates from human carriage and infection (Table 5).

\section{Discussion}

We assessed the import and potential spread of ESBL $E$. coli and S. aureus through chicken meat in Gabon, Central Africa. Main findings were a high proportion of imported chicken meat in our sample collection and a high prevalence of ESBL E. coli. Beta-lactamases associated with chicken meat were not found in ESBL E. coli from carriage and infection in humans. Chicken-related S. aureus genotypes were found in human isolates from carriage and infection.

The high proportion of imported chicken products in Gabon is not surprising because the country has an excess of import of poultry meat. The import of poultry products increased in Gabon from 11,149 Mt (1997) to $43,875 \mathrm{Mt}$ (2007), the ratio of exports to imports in 2007 was 0.0 (Germany: 0.8, http://kids.fao.org/glipha).

No ESBL Enterobacteriaceae other than ESBL E. coli were detected which is in line with recent reports where the proportion of ESBL E. coli among all ESBLproducers from chicken was $93.8 \%$ (Germany), 76.8\% (the Netherlands) and 58-67\% (Spain) $[8,11,15]$. The prevalence of ESBL E. coli in chicken meat was lower in chicken products from the US compared to Spain which could be explained by a generally lower ESBL $E$. coli contamination rate in chicken from the US [11]. This lower contamination rate might be achieved by a "pathogen reduction treatment" with chemical compounds (e. g. chlorinated water) in the US which is prohibited in the European Union [16].

The predominance of the phylogenetic groups $\mathrm{A}$ and B1 in poultry products was expected as these groups are mostly found in the environment in contrast to B2 which is associated with mammals [17].

The ESBL encoding genes found in chicken meat in Gabon mainly belonged to CTX-M 1 and CTX-M 14 (Table 3). The predominance of CTX-M 14 over CTX-M 1 reflects the proportion of CTX-M subtypes in Spain [7]. Our data do not provide any evidence for a transmission

Table 2 Sources of ESBL E. coli and S. aureus isolates from human carriage and infection

\begin{tabular}{|c|c|c|c|c|}
\hline \multirow[t]{2}{*}{ Characteristics } & \multicolumn{2}{|l|}{ ESBL E. coli } & \multicolumn{2}{|l|}{ S. aureus } \\
\hline & Carriage $(n=16)$ & Infection $(n=10)$ & Carriage $(n=20)$ & Infection $(n=21)$ \\
\hline Year of collection & $2010-2011$ & $2010-2013$ & 2011 & 2012 \\
\hline Median age (range) & $1.5(0.8-12.5)$ & $3.1(0.2-68.8)$ & $24.5(6.5-37.3)$ & $1.6(0.2-36.2)$ \\
\hline Females, n (\%) & $7(43.8 \%)$ & $4(44.4 \%)$ & $11(55 \%)$ & $9(42.9)$ \\
\hline Type of samples (n) & Rectal swabs (16) & Wound swabs (3), urine (2), others (5) & Nasal swabs (20) & Abscess (9), skin and soft tissue infection (12) \\
\hline Reference & [14] & Routine diagnostics & {$[31]$} & Routine diagnostics \\
\hline
\end{tabular}


Table 3 Characteristics of ESBL E. coli from poultry, colonization and infection in humans in Gabon

\begin{tabular}{|c|c|c|c|c|}
\hline & & $\begin{array}{l}\text { Chicken meat } \\
(n=17)\end{array}$ & $\begin{array}{l}\text { Carriage } \\
(n=16)\end{array}$ & $\begin{array}{l}\text { Infection } \\
(n=10)\end{array}$ \\
\hline \multirow{4}{*}{$\begin{array}{l}\text { Phylogenetic } \\
\text { group }\end{array}$} & $A$ & $13(76.5 \%)$ & $9(56.3 \%)$ & $2(20 \%)$ \\
\hline & B1 & $3(17.7 \%)$ & $4(25.0 \%)$ & $3(30 \%)$ \\
\hline & B2 & - & $2(12.5 \%)$ & $3(30 \%)$ \\
\hline & $D$ & $1(5.9 \%)$ & $1(6.3 \%)$ & $2(20 \%)$ \\
\hline \multirow[t]{7}{*}{ Beta lactamases } & CTX-M 1 & $4(23.5 \%)$ & - & - \\
\hline & CTX-M 14 & $6(35.3 \%)$ & - & - \\
\hline & CTX-M 15 & - & $16(100 \%)$ & $9(90 \%)$ \\
\hline & CTX-M 27 & - & - & $1(10 \%)$ \\
\hline & CTX-M 32 & $1(5.9 \%)$ & - & - \\
\hline & TEM & $6(35.3 \%)$ & 7 (43.8\%) & $3(30 \%)$ \\
\hline & SHV & 7 (41.2\%) & - & $1(10 \%)$ \\
\hline \multirow{7}{*}{$\begin{array}{l}\text { Antibiotic } \\
\text { resistance, } \\
\text { tested } \\
\text { substances }\end{array}$} & $\begin{array}{l}\text { Piperacillin/ } \\
\text { Tazobactam }\end{array}$ & $1(5.9 \%)$ & $5(31.2 \%)$ & $1(10 \%)$ \\
\hline & Cefuroxim & 15 (88.2\%) & 16 (100\%) & $10(100 \%)$ \\
\hline & Cefotaxim & $12(70.6 \%)$ & 16 (100\%) & $10(100 \%)$ \\
\hline & Ceftazidim & 7 (41.2\%) & $14(87.5 \%)$ & $10(100 \%)$ \\
\hline & Gentamicin & $6(35.3 \%)$ & $5(31.2 \%)$ & $4(40 \%)$ \\
\hline & Ciprofloxacin & $8(47.1 \%)$ & 9 (56.2\%) & $8(80 \%)$ \\
\hline & Cotrimoxazole & $3(17.6 \%)$ & 15 (93.8\%) & 10 (100\%) \\
\hline
\end{tabular}

Note: all figures are no (\%), "-“ denotes $0(0 \%)$.

of ESBL E. coli from poultry to humans as CTX-M 1 and CTX-M 14 from chicken meat were neither detected in ESBL E. coli from carriage nor infection in humans (Table 3). This is in contrast to Europe and the Americas, where CTX-M 1 was the most common beta-lactamase in ESBL E. coli from humans [18].

It is unclear why the same ESBL subtype (CTX-M 1) occur in poultry related and human isolates in Europe but not in Gabon [18]. One might argue that the prevalence and concentration of ESBL E. coli in chicken meat in Gabon is not yet high enough to be transmitted and to establish a sustainable colonization in humans [19]. It is also possible, that our samples size was too small to detect CTX-M subtypes with lower prevalence such as CTX-M 1 which accounts for 7\% of all ESBL/AmpC types in humans in Europe [18].

Chicken meat can be contaminated not only with ESBL Enterobacteriaceae but also with $S$. aureus and MRSA, in particular. S. aureus research in livestock animals has been focused on MRSA. The prevalence of MRSA in poultry products is up to $37.2 \%$ in Germany $[10,20]$, but varies significantly within and between the different countries in Europe (0\% in Switzerland, 6.9\% in the Netherlands) $[10,12]$. This variation in MRSA
Table 4 Comparison of spa types and MLST STs of S. aureus from poultry, carriage and infection in humans in Gabon

\begin{tabular}{|c|c|c|c|c|}
\hline \multirow{2}{*}{$\begin{array}{l}\text { Clonal } \\
\text { complex }\end{array}$} & \multirow{2}{*}{$\begin{array}{l}\text { Sequence } \\
\text { type }\end{array}$} & \multicolumn{3}{|l|}{ Spa type (n) } \\
\hline & & $\begin{array}{l}\text { Chicken meat } \\
(n=5)\end{array}$ & $\begin{array}{l}\text { Carriage } \\
(n=20)\end{array}$ & $\begin{array}{l}\text { Infection } \\
(\mathrm{n}=21)\end{array}$ \\
\hline \multirow[t]{9}{*}{$\mathrm{CC5}$} & ST5 & t002 (3) & $\begin{array}{l}\text { t002 (1), t045 (1), } \\
\text { t653 (1) }\end{array}$ & $\mathrm{t} 319(1)$ \\
\hline & ST8 & - & t008 (1) & $\begin{array}{l}\mathrm{t} 1476(2), \\
\mathrm{t} 121(1)\end{array}$ \\
\hline & ST9 & - & t1045 (1) & - \\
\hline & ST15 & - & t7583 (1) & t084 (6) \\
\hline & ST25 & - & - & - \\
\hline & ST72 & - & t9147 (1) & - \\
\hline & ST97 & - & t311 (1) & - \\
\hline & ST2666 & - & t084 (2) & - \\
\hline & $\begin{array}{l}\text { Non } \\
\text { typable }\end{array}$ & t591 (1) & - & - \\
\hline \multirow[t]{2}{*}{ CC45 } & ST45 & - & t939 (3), t6552 (2) & - \\
\hline & ST508 & - & t9149 (1), t2194 (2) & - \\
\hline CC121 & ST2702 & - & - & $\mathrm{t} 272(1)$ \\
\hline CC152 & ST152 & - & t355 (1), t454 (1) & t355 (9) \\
\hline CC398 & ST398 & - & - & - \\
\hline CC707 & ST707 & - & - & - \\
\hline \multirow[t]{2}{*}{ Singletons } & ST1193 & - & - & $346(1)$ \\
\hline & ST2622 & t386 (1) & - & - \\
\hline
\end{tabular}

Note: not detected (-).

colonization might be the reason why we did not detect any MRSA among the $S$. aureus isolates in our study. Nevertheless, genotyping of methicillin susceptible $S$. aureus (MSSA) revealed that some $S$. aureus from poultry meat and humans in Gabon share the same spa type (t002, ST5). On the one hand, it was postulated that a human-to-poultry transmission of S. aureus ST5 isolates occurred in the $1980 \mathrm{~s}$ and that this clonal lineage now spreads in chicken around the world (except for Australia, where stringent controls of imported poultry products are applied) [21]. On the other hand,

Table 5 Antimicrobial resistance of $S$. aureus from chicken meat, carriage and infection in humans in Gabon

\begin{tabular}{llll}
\hline & $\begin{array}{l}\text { Chicken meat } \\
(\mathbf{n = 5})\end{array}$ & $\begin{array}{l}\text { Carriage } \\
(\mathbf{n = 2 0 )}\end{array}$ & $\begin{array}{l}\text { Infection } \\
(\mathbf{n = 2 1 )}\end{array}$ \\
\hline Penicillin & $1(20 \%)$ & $20(100 \%)$ & $21(100 \%)$ \\
Oxacillin & $0(0 \%)$ & $1(5 \%)$ & $1(4.8 \%)$ \\
Gentamicin & $0(0 \%)$ & $1(5 \%)$ & $0(0 \%)$ \\
Erythromycin & $0(0 \%)$ & $4(20 \%)$ & $1(4.8 \%)$ \\
Clindamycin & $0(0 \%)$ & $0(0 \%)$ & $0(0 \%)$ \\
Tetracycline & $2(40 \%)$ & $5(25 \%)$ & $14(66.7 \%)$ \\
Cotrimoxazole & $0(0 \%)$ & $4(20 \%)$ & $12(57.1 \%)$ \\
\hline
\end{tabular}

Note: all figures are no (\%). 
there might be a risk of transmission of isolates belonging to t002 back to humans [22].

Although our study provides important information about the spread of pathogens through the trade with chicken products, some limitations need to be addressed. First, the prevalence of $S$. aureus in chicken meat in Gabon might have been underestimated as we did not use S. aureus selective enrichment broths and chromogenic agars. This practice was chosen because our objective was to use preferentially methods which can be easily applied in rather basally equipped laboratories. Second, few months after the start of the study we realized the high burden of ESBL-producing Enterobacteriaceae in humans Gabon [14]. From that point, we decided to use chromogenic media for the screening of ESBL E. coli in chicken meat. Therefore only a proportion of samples were consecutively screened for ESBLproducing Enterobacteriaceae (60 of 151, Table 1). Third, more comprehensive genotyping approaches (e.g. sequencing of plasmids) would have been preferred to detect more reliably potential sources of transmission. Fourth, our results might not be representative for the whole country due to the small sample size. Fifth, due to the cross sectional study design we cannot draw any conclusions regarding the direction of transmission between chicken meat and humans, in case there is any. Sixth, the chromogenic agar that we used might suppress the growth of Enterobacteriaceae carrying the AmpC resistance type. Therefore, the prevalence of CMY-2 refers to ESBLproducers only.

\section{Conclusions}

In conclusion, there is a risk to import ESBL E. coli to Gabon but molecular differences between isolates from humans and chicken meat argue against a further dissemination. No MRSA isolate was imported through poultry meat.

\section{Methods}

\section{Ethical clearance}

No ethical approval was sought to analyze chicken meat samples. In Gabon, no ethical approval is requested if already existing isolates from clinical samples are analysed [23]. Ethical clearance was obtained from our institutional review board (IRB) in Lambaréné to collect swabs from asymptomatic healthy carriers (Comité d'Éthique Régional Indépendant de Lambaréné, CERIL). The ESBL Enterobacteriaceae from carriers derived from children and the legal representative of each child gave documented oral informed consent prior to enrolment [14]. The IRB approved the use of documented oral informed consent to collect rectal swabs from children (CERIL 09/2010). Written informed consent was given to screen for nasal colonization with $S$. aureus. The use of written informed consent to obtain nasal swabs was approved by our IRB (CERIL 15/2009).

\section{Sample collection}

In a cross sectional study, samples from frozen chicken meat (wing, leg) sold at five commercial markets in Lambaréné, Gabon were randomly collected from December 2011 to November 2012. All samples were originally designated for human consumption and were stored in freezers until sampling. The country of origin and the species (i.e. chicken) were recorded according to declarations on the packaging. To guarantee sterile sampling conditions, approximately $5 \mathrm{~g}$ of meat were sampled using gloves, sterile forceps and scalpels. Only one sample per selling unit/batch was taken. Samples were stored at $-20^{\circ} \mathrm{C}$ until microbiological culture.

Our initial objective was to investigate the occurrence of $S$. aureus in chicken meat, but since a recent study showed a high carriage rate of ESBL Enterobacteriaceae in Gabonese children, we also included the screening for ESBL Enterobacteriaceae after beginning of the study (Table 1) [14].

The poultry-related isolates were compared with ESBL Enterobacteriaceae (matched for species found in chicken meat samples) and $S$. aureus from humans (carriage and infection) from already existing strain collections (Table 2).

Human isolates from infection derived from routine diagnostics of the Albert Schweitzer Hospital, Lambaréné, Gabon and were consecutively collected.

\section{Detection of ESBL-producing Enterobacteriaceae}

The meat samples were directly streaked on colorimetric ESBL-selective agar plates (bioMérieux, Marcy l'Etoile, France). After overnight culture in non-selective brainheart-infusion enrichment broth, the samples were again plated on ESBL-selective agar plates. Colorimetric colonies on ESBL-plates were subjected to species identification and susceptibility testing using Vitek 2 automated systems (bioMérieux).

Antimicrobial resistance was evaluated using EUCAST breakpoints for susceptibility testing (Version 3.1, 2011); susceptibility of ESBL-producing Enterobacteriaceae to beta-lactams was reported as found. We confirmed the ESBL phenotype by double-disc diffusion tests according to the manufacturer's instruction (Mast discs, Mast diagnostics, Bootle, UK). A PCR was used to detect the genes encoding the beta-lactamases $b l a_{\mathrm{SHV}}, b l a_{\mathrm{TEM}}, b l a_{\mathrm{CTX}-\mathrm{M}}$ and $b l a_{\mathrm{CMY}-2}$; the $b l a_{\text {СтX-M }}$ genes were sequenced for subtyping $[24,25]$.

\section{Detection of Staphylococcus aureus}

The meat samples were directly streaked on Columbia blood agar plates supplemented with aztreonam disks (13 $\mu \mathrm{g}$; Oxoid, Hants, UK). After overnight culture in 
non-selective brain-heart-infusion enrichment broth, the samples were again plated on Columbia blood agar (supplemented with aztreonam disks). S. aureus was identified by standard procedures including an agglutination test (Pastorex Staph-Plus; Bio-Rad Laboratories, Marnes-laCoquette, France). Presumptive S. aureus colonies were subjected to species identification and susceptibility testing using Vitek 2 automated systems (bioMérieux). Species confirmation was done by the detection of nuc [26].

Antimicrobial resistance was evaluated using EUCAST breakpoints for susceptibility testing (Version 3.1, 2011); Resistance to penicillin and oxacillin were confirmed by the detection of blaZ and $m e c A$, respectively [26,27].

\section{Genotyping}

Each ESBL E. coli isolate was assigned to its phylogenetic group (A, B1, B2, D) according to the genetic pattern of chuA, yjaA and the anonymous DNA Fragment TSPE4.C2 [28]. S. aureus was spa typed and multilocus sequence typing (MLST) was done exemplarily for one isolate of each spa type for each group (chicken, carriage and infection in humans) [29-31]. MLST clonal complexes (CC) were determined with eBURST using the whole MLST dataset and the stringent group definition of six of seven shared alleles (http://saureus.mlst.net/eburst).

\section{Statistics}

Associations between categorical variables were tested using Fisher's exact test. The odds ratio (OR) and 95\% confidence interval $(95 \% \mathrm{CI})$ were calculated to assess the strength of association. The significance level was set at 5\%. Statistical analyses were performed using "R" (http:// cran.r-project.org) and the package "Epicalc". The map was created with "R" and the package "Maps".

\section{Abbreviations}

CC: Clonal complex; ESBL: Extended-spectrum beta-lactamase; MLST: Multilocus sequence typing; MRSA: Methicillin-resistant Staphylococcus aureus;

ST: Sequence type.

\section{Competing interests}

The authors declare that they have no competing interests.

\section{Authors' contribution}

FS, ASA and AM were involved in the conception, design and analysis of the study. Microbiological analyses were done by FS, LF, RK, and AM. FS, MPG, KB, SI, PGK, GP and AM drafted the manuscript or revised critically the results. All authors read and approved the final manuscript.

\section{Acknowledgement}

We are grateful for excellent technical help from Harry Kaba (Lambaréné), Damayanti Kaiser and Heike Rengbers (Münster). We are grateful to Martin Kaase (Bochum) for providing positive control strains.

This work was supported by the Deutsche Forschungsgemeinschaft (DFG, El 247/8-1 and ME 3205/4-1), by a grant of the Medical Faculty of the University of Münster (BD9817044) and the Open Access Publication Fund of the University of Münster.

\section{Author details}

'Institute of Medical Microbiology, University Hospital Münster, Domagkstr. 10, 48149 Münster, Germany. ${ }^{2}$ Centre de Recherches Médicales de Lambaréné, Albert Schweitzer Hospital, Lambaréné, Gabon. ${ }^{3}$ Institut für Tropenmedizin, Eberhard Karls Universität and Deutsches Zentrum für Infektionsforschung, Tübingen, Deutschland. ${ }^{4}$ Department of Infectious Diseases, Division of Internal Medicine, Center for Tropical Medicine and Travel Medicine, Academic Medical Center, University of Amsterdam, Amsterdam, The Netherlands. ${ }^{5}$ Institute of Hygiene, University Hospital Münster, Münster, Germany.

Received: 5 August 2014 Accepted: 6 November 2014

Published online: 19 November 2014

\section{References}

1. Weiss RA, McMichael AJ: Social and environmental risk factors in the emergence of infectious diseases. Nat Med 2004, 10:S70-S76.

2. Karch H, Denamur E, Dobrindt U, Finlay BB, Hengge R, Johannes L, Ron EZ, Tønjum T, Sansonetti PJ, Vicente M: The enemy within us: lessons from the 2011 European Escherichia coli 0104:H4 outbreak. EMBO Mol Med 2012, 4:841-848.

3. Zanger $\mathrm{P}$, Nurjadi $\mathrm{D}$, Schleucher $\mathrm{R}$, Scherbaum H, Wolz C, Kremsner PG, Schulte B: Import and Spread of Panton-Valentine Leukocidin-Positive Staphylococcus aureus Through Nasal Carriage and Skin Infections in Travelers Returning From the Tropics and Subtropics. Clin Infect Dis 2012, 54:483-492.

4. Tängdén T, Cars O, Melhus $\AA$, Löwdin E: Foreign Travel Is a Major Risk Factor for Colonization with Escherichia coli Producing CTX-M-Type Extended-Spectrum b-Lactamases: a Prospective Study with Swedish Volunteers. Antimicrob Agents Chemother 2010, 54:3564-3568.

5. Rogers BA, Aminzadeh Z, Hayashi Y, Paterson DL: Country-to-Country Transfer of Patients and the Risk of Multi-Resistant Bacterial Infection. Clin Infect Dis 2011, 53:49-56.

6. Singer RS, Finch R, Wegener HC, Bywater R, Walters J, Lipsitch M: Antibiotic resistance-the interplay between antibiotic use in animals and human beings. Lancet Infect Dis 2003, 3:47-51

7. Egea P, López-Cerero L, Torres E, del Carmen G-SM, Serrano L, Navarro Sánchez-Ortiz MD, Rodriguez-Baño J, Pascual A: Increased raw poultry meat colonization by extended spectrum beta-lactamase-producing Escherichia coli in the south of Spain. Int J Food Microbiol 2012, 159:69-73.

8. Overdevest I, Willemsen I, Rijnsburger M, Eustace A, Xu L, Hawkey P, Heck M, Savelkoul P, Vandenbroucke-Grauls C, van der Zwaluw K, Huijsdens X, Kluytmans J: Extended-spectrum beta-lactamase genes of Escherichia coli in chicken meat and humans, The Netherlands. Emerg Infect Dis 2011, 17:1216-1222

9. Lozano C, López M, Gómez-Sanz E, Ruiz-Larrea F, Torres C, Zarazaga M: Detection of methicillin-resistant Staphylococcus aureus ST398 in food samples of animal origin in Spain. J Antimicrob Chemother 2009, 64:1325-1326

10. Feßler AT, Kadlec K, Hassel M, Hauschild T, Eidam C, Ehricht R, Monecke S, Schwarz S: Characterization of Methicillin-Resistant Staphylococcus aureus Isolates from Food and Food Products of Poultry Origin in Germany. Appl Environ Microbiol 2011, 77:7151-7157.

11. Doi Y, Paterson DL, Egea P, Pascual A, López-Cerero L, Navarro MD, Adams-Haduch JM, Qureshi ZA, Sidjabat HE, Rodríguez-Baño J: Extendedspectrum and CMY-type b-lactamase-producing Escherichia coli in clinical samples and retail meat from Pittsburgh, USA and Seville, Spain. Clin Microbiol Infect 2010, 16:33-38.

12. Mulders MN, Haenen APJ, Geenen PL, Vesseur PC, Poldevaart ES, Bosch T, Huijsdens XW, Hengeveld PD, Dam-Deisz WDC, Graate EAM, Mevius DJ, Voss A, Van de Giessen AW: Prevalence of livestock-associated MRSA in broiler flocks and risk factors for slaughterhouse personnel in The Netherlands. Epidemiol Infect 2010, 138:743-755.

13. Kluytmans JAJW, Overdevest ITMA, Willemsen I, Kluytmans-van den Bergh M, van der Zwaluw K, Heck M, Rijnsburger M, Vandenbroucke-Grauls CMJE, Savelkoul PHM, Johnston BD, Gordon D, Johnson JR: Extended-Spectrum b-Lactamase-Producing Escherichia coli From Retail Chicken Meat and Humans: Comparison of Strains, Plasmids, Resistance Genes, and Virulence Factors. Clin Infect Dis 2013, 56:478-487.

14. Schaumburg F, Alabi A, Kokou C, Grobusch MP, Köck R, Kaba H, Becker K, Adegnika AA, Kremsner PG, Peters G, Mellmann A: High burden of 
extended-spectrum ß-lactamase-producing Enterobacteriaceae in Gabon. J Antimicrob Chemother 2013, 68:2140-2143.

15. Kola A, Kohler C, Pfeifer Y, Schwab F, Kühn K, Schulz K, Balau V, Breitbach K, Bast A, Witte W, Gastmeier P, Steinmetz I: High prevalence of extendedspectrum-b-lactamase-producing Enterobacteriaceae in organic and conventional retail chicken meat, Germany. J Antimicrob Chemother 2012, 67:2631-2634

16. Alonso-Hernando A, Alonso-Calleja C, Capita R: Effectiveness of several chemical decontamination treatments against Gram-negative bacteria on poultry during storage under different simulated cold chain disruptions. Food Control 2013, 34:574-580.

17. Gordon DM, Clermont O, Tolley H, Denamur E: Assigning Escherichia coli strains to phylogenetic groups: multi-locus sequence typing versus the PCR triplex method. Environ Microbiol 2008, 10:2484-2496.

18. Ewers C, Bethe A, Semmler T, Guenther S, Wieler LH: Extended-spectrum b-lactamase-producing and AmpC-producing Escherichia coli from livestock and companion animals, and their putative impact on public health: a global perspective. Clin Microbiol Infect 2012, 18:646-655.

19. Horton RA, Randall LP, Snary EL, Cockrem H, Lotz S, Wearing H, Duncan D, Rabie A, McLaren I, Watson E, La Ragione RM, Coldham NG: Fecal Carriage and Shedding Density of CTX-M Extended-Spectrum b-LactamaseProducing Escherichia coli in Cattle, Chickens, and Pigs: Implications for Environmental Contamination and Food Production. Appl Environ Microbiol 2011, 77:3715-3719

20. Monecke S, Ruppelt A, Wendlandt S, Schwarz S, Slickers P, Ehricht R, Cortez deJäckel S: Genotyping of Staphylococcus aureus isolates from diseased poultry. Vet Microbiol 2013, 162:806-812.

21. Lowder BV, Guinane CM, Ben Zakour NL, Weinert LA, Conway-Morris A Cartwright RA, Simpson AJ, Rambaut A, Nübel U, Fitzgerald JR: Recent human-to-poultry host jump, adaptation, and pandemic spread of Staphylococcus aureus. Proc Natl Acad Sci U S A 2009, 106:19545-19550.

22. Hasman H, Moodley A, Guardabassi L, Stegger M, Skov RL, Aarestrup FM: spa type distribution in Staphylococcus aureus originating from pigs, cattle and poultry. Vet Microbiol 2010, 141:326-331.

23. Alabi A, Frielinghaus L, Kaba H, Kosters K, Huson MA, Kahl B, Peters G, Grobusch M, Issifou S, Kremsner P, Schaumburg F: Retrospective analysis of antimicrobial resistance and bacterial spectrum of infection in Gabon. Central Africa BMC Infect Dis 2013, 13:455.

24. Monstein HJ, Östholm-Balkkhed Å, Nilsson P, Nilsson MV, Dornbusch K Nilsson LE: Multiplex PCR amplification assay for the detection of ${ }^{\text {bla }} \mathrm{SHV}$, ${ }^{b l a}$ TEM and ${ }^{b / a}$ CTX-M genes in Enterobacteriaceae. APMIS 2007, 115:1400-1408.

25. Souna D, Amir AS, Bekhoucha SN, Berrazeg M, Drissi M: Molecular typing and characterization of TEM, SHV, CTX-M, and CMY-2 b-lactamases in Enterobacter cloacae strains isolated in patients and their hospital environment in the west of Algeria. Med Mal Infect 2014, 44:146-152.

26. Becker K, Pagnier I, Schuhen B, Wenzelburger F, Friedrich AW, Kipp F, Peters $G$, von Eiff C: Does nasal cocolonization by methicillin-resistant coagulase-negative staphylococci and methicillin-susceptible Staphylococcus aureus strains occur frequently enough to represent a risk of false-positive methicillin-resistant $S$. aureus determinations by molecular methods? J Clin Microbiol 2006, 44:229-231.

27. Kaase M, Lenga S, Friedrich S, Szabados F, Sakinc T, Kleine B, Gatermann SG: Comparison of phenotypic methods for penicillinase detection in Staphylococcus aureus. Clin Microbiol Infect 2008, 14:614-616.

28. Clermont O, Bonacorsi S, Bingen E: Rapid and Simple Determination of the Escherichia coli Phylogenetic Group. Appl Environ Microbiol 2000, 66:4555-4558.

29. Enright MC, Day NP, Davies CE, Peacock SJ, Spratt BG: Multilocus sequence typing for characterization of methicillin-resistant and methicillinsusceptible clones of Staphylococcus aureus. J Clin Microbiol 2000, 38:1008-1015

30. Mellmann A, Friedrich AW, Rosenkotter N, Rothganger J, Karch H, Reintjes R, Harmsen D: Automated DNA sequence-based early warning system for the detection of methicillin-resistant Staphylococcus aureus outbreaks. PLOS Med 2006, 3:e33.
31. Ruffing U, Akulenko R, Wende L, Schubert S, Kazimoto T, Vubil D, Alabi AS, Herrmann M, Schaumburg F, Kern W: DNA microarray-based genotyping of 1200 Staphylococcus aureus isolates of the African-German StaphNet multicentre study [abstract]. In 24 European Congress of Clinical Microbiology and Infectious Diseases. Barcelona, Spain: European Society of Clinical Microbiology and Infectious Diseases; 2014.

doi:10.1186/s12866-014-0286-3

Cite this article as: Schaumburg et al:: The risk to import ESBL-producing Enterobacteriaceae and Staphylococcus aureus through chicken meat trade in Gabon. BMC Microbiology 2014 14:286.

\section{Submit your next manuscript to BioMed Central and take full advantage of:}

- Convenient online submission

- Thorough peer review

- No space constraints or color figure charges

- Immediate publication on acceptance

- Inclusion in PubMed, CAS, Scopus and Google Scholar

- Research which is freely available for redistribution

Submit your manuscript at www.biomedcentral.com/submit
C Biomed Central 